\title{
THE DEVELOPMENT OF BLOOD GAS ANALYSIS
}

\author{
by
}

\section{S. BREATHNACH}

TRUTH Is more likely to come out of error than confusion. Lavoisier's assumption that combustion occurred in the lungs did not go unchallenged, but blood gas analysis remained uncertain until the physicist, Gustav Magnus, introduced a reliable vacuum pump. Physiologists, from Bernard and Ludwig down, joined in the investigation, and then, just as tissue metabolism was established, came Haldane's insistence on pulmonary secretion of oxygen, the stimulus to one of biology's most fertile controversies.

\section{VACUUM PUMPS}

By means of the vacuum pump specially contrived by himself and Robert Hooke, Robert Boyle in 1670 obtained air from blood. John Mayow's fuliginous vapourings concerning nitro-aerial spirit notwithstanding, it was not until Black (1754-1756) published details for the recognition of 'fixed air' (i.e. carbon dioxide) and Lavoisier (1777-79) described the 'eminently respirable' part of the air (1777) and named it oxygen (1779), recognizing Priestley's (1774) 'dephlogisticated air' for what it was that any further advance was possible (Table 1).

Table 1

Landmarks in the evolution of gas chemistry

\begin{tabular}{|l|l|l|c|}
\hline \multicolumn{1}{|c|}{ Gas } & \multicolumn{1}{|c|}{ Pseudonym } & \multicolumn{1}{c|}{ Discoverer } & Date \\
\hline carbon dioxide & fixed air & Joseph Black & 1754,1756 \\
hydrogen & & Henry Cavendish & 1766 \\
nitrogen & & Daniel Rutherford & 1772 \\
oxygen & & Joseph Priestley & 1774 \\
& dephlogisticated air & Antoine Lavoisier & 1777,1779 \\
\hline
\end{tabular}

The first consistent analyses of blood gases were made by Gustav Magnus, professor of physics and technology in Berlin. Magnus (1837a) described how he passed carbon dioxide-free hydrogen through venous blood collected from the jugular vein of horses and from 'commoners who for a small sum permitted themselves to be bled'. 


\section{S. Breathnach}

He found $16.6 \mathrm{ml}$. of carbonic acid gas in $66.8 \mathrm{ml}$. of venous blood, in itself evidence against Lavoisier's assumption. Magnus (1837b) also analysed both arterial and venous blood samples in his mercurial blood pump. A six-inch glass tube closed at one end was connected through two stopcocks to a flask, the lower end of which dipped into a dish of mercury. By placing this vessel in a sealed belljar evacuated by a 'pneumatic machine', a Torricellian vacuum could be produced in the flask and blood introduced therein. The gases extracted from the blood by the vacuum rose into the closed tube from which transfer to a eudiometer for analysis was facilitated by the stopcock arrangement. Carbon dioxide was determined by absorption in caustic potash and noting the change in weight of the potash. Detonation of the remainder gas with hydrogen made oxygen determination possible. Magnus estimated that the blood contained 4.8 volumes per cent (vol \%) carbon dioxide, 1 to $3.5 \mathrm{vol} \%$ oxygen and 0.5 to 2 vol \% nitrogen. These estimates, of course, are invariably far too low but he consistently found more oxygen in arterial than in venous blood. Applying the laws of the physicist, Magnus (1837a) explained gas exchange in the lung as diffusion remarking 'that the quantity of carbonic acid contained in venous blood is more than sufficient to furnish the quantity expired. . . . It is . . . likely that the oxygen is inhaled and absorbed in the lung by the blood which carries it thence throughout the body, where it is released in the capillaries with associated production of carbonic acid.'

Magnus (1845) went on to attempt to estimate the oxygen capacity of the blood. He used a drop of oil, placed on the surface of the blood, as an anti-foam agent and shrewdly remarked: 'The proportion of oxygen to nitrogen in the gas released from the blood is further direct proof that during the experiment atmospheric air has not leaked into the vessel-in which case the proportion would be as it is in atmospheric air, but here the oxygen amounted to three, four and even five times as much as the nitrogen.'

As late as 1830 Collard de Martigny had failed to identify any other constituent than carbon dioxide in the gas extracted from blood, and it was in the wake of Magnus's (1845) detailed answer to Gay Lussac's criticism-'eine Kritik Meiner schon'-that the mercurial gas-pumps, using the principle of the Torricellian vacuum, were developed. An important modification arose by combination with another approach. Humphry Davy (1803) found that by heating blood to $93^{\circ} \mathrm{C} 1.1$ volumes of carbonic acid and 0.7 volumes of oxygen were given off by 12 volumes of blood, and Lothar Meyer (1857) working in Bunsen's laboratory developed the method in his absorptiometer. During the summer of 1858 Setchenow came to Carl Ludwig's laboratory in Vienna, and there used Meyer's absorptiometer as a pump. Thus it was possible to renew the vacuum as well as heat the blood, and an improved model was 'constructed according to the specifications of Professor Ludwig' (Setchenow, 1859). The results are worth recalling (Table 2). Setchenow (1865) modified the pump for easier manipulation, but it would seem that the most popular continental version was that introduced by Pfluger (Pfluger, 1866; Zuntz, 1867; Pfluger and Zuntz, 1868), which included a froth chamber above the blood receiver and utilized sulphuric acid to absorb water vapour and caustic potash to absorb carbon dioxide.

Under Lothar Meyer's guidance Nawrocki (1863) compared results obtained with 
Table 2

Blood gas volumes, expressed in volumes of gas per 100 volumes of blood, reported by Setchenow and Ludwig in 1859

\begin{tabular}{|c|c|c|c|c|}
\hline \multirow{2}{*}{ sample } & oxygen & nitrogen & \multicolumn{2}{|c|}{ farbon dioxide } \\
& & & free & combined \\
\hline 1 & 15.05 & 1.19 & 30.66 & 2.54 \\
2 & 16.41 & 1.20 & 28.27 & 2.32 \\
\hline
\end{tabular}

Ludwig and Setchenow's pump with those given by a novel method evolved from his experimental investigation of the toxicity of carbon monoxide by Claude Bernard (1858). Whereas the volume of oxygen or of carbon dioxide fell when either gas was exposed to blood, that of carbon monoxide remained the same; on analysis, however the carbon monoxide contained an admixture of oxygen, the source of which must have been the blood. Blood previously shaken up with carbon dioxide was capable of taking up oxygen when exposed to that gas, blood treated with carbon monoxide was not; the carbon monoxide was capable of paralysing the respiratory function of the blood 'globules' (i.e. red blood cells), and, Bernard reasoned, should also be capable of releasing oxygen from the blood. After exposure of the blood to carbon monoxide, the carbon dioxide in the evolved gas was absorbed by caustic potash, and the oxygen by pyrogallic acid. By means of an electric spark the carbon monoxide was oxidised to carbon dioxide and determined as such. Nawrocki (1863) showed that the results with the two methods were comparable, but Bernard's method was as tedious as the pumps were cumbrous, and fell into desuetude even amongs this own disciples.

Franco-Prussian rivalry extended even to the mercurial gas-pump. Paul Bert (1878) described a water-jacket, 'the idea of M. Grehant', used to cool the froth chamber of the pump, but was also concerned with the origin of the apparatus:

The invention of the mercury pump is usually attributed to German technicians and with the love of foreign advertising customary to us we often decorate this instrument with the name of 'Geissler pump'. The truth is that the invention belongs in principle to M. Regnault. Long ago, this famous professor of the College de France invented a similar pump, equipped with a three-way cock, which is the most important part of the instrument. But instead of using a movable reservoir, because at that time rubber was seldom used in the construction of apparatus, he put his barometer tube in communication with two reservoirs, one above and one below; this required, of course, a rather complicated system of tubes and cocks. But the principle was the same, and the addition of a rubber tube is certainly not of sufficient importance to make us forget the real inventor.

The zinc cuff with its circulating water with which Grehant surrounded the froth chamber was an essential addition, for frothing was increased considerably by Bert's practice of heating the blood even to $100^{\circ} \mathrm{C}$. His results with oxygen were extremely good, and in a few experiments his carbon dioxide values would be quite acceptable today. By means of an apparatus constructed to bring blood into contact with air 


\title{
C. S. Breathnach
}

at a specified decrease in pressure, Bert obtained figures which would fit very well the upper half of the oxygen dissociation curve. It was Paul Bert, of course, who showed that it was the low pressure of oxygen, not simply the lowered barometric pressure, which was fatal at high altitude.

The blood gas-pump reached its simplest form in the hands of Leonard Hill (1894-5); its construction clarifies the principles underlying all such pumps (Fig. 1); and the course of an analysis illustrates its simplicity:

\begin{abstract}
A blood receiver (F) is affixed to the end of the tube $\mathrm{E}$, and the receiver is elevated into the position indicated by the dotted outline. The reservoir (B) is then put in connection with the tube (E) by means of the three-way tap (D), the reservoir (A) is raised above the pump, and the whole system is filled with mercury to the top of the blood reservoir (F). The screw-clip on the rubber tube at the upper end of $F$ is then closed, and the reservoir (A) lowered until the blood-receiver is exhausted, except for 2 or 3 cc. of mercury. The screw-clip on the lower end of $F$ is next closed, and the blood receiver now clipped at either end, exhausted, detached from tube E, and weighed. A sample of blood is then collected. The arterial or venous cannula is filled with blood, and immediately afterwards pushed into the rubber tube at the end of the blood-receiver, as far as the closed screw-clip. Before the insertion of the cannula, the end of the rubber tube is compressed with the fingers to exclude the air within it. A sufficient quantity of blood is now withdrawn by opening at the same time the screw-clip and the clip placed on the blood vessel of the animal. The blood is defibrinated by shaking it with the mercury left within the blood receiver for that purpose, and the latter is then again weighed. The weight of the sample of blood is then obtained. The blood-receiver is next affixed once more to the tube (E), in the dependent position shown in the figure, and the tube $(E)$ is exhausted. Finally the screw-clip between $E$ and the blood-receiver is opened, and the gases are withdrawn and collected in the eudiometer. Since the blood-receiver hangs freely from the tube (E) by means of a piece of rubber tubing, it can be both immersed in warm water, and shaken to facilitate the complete escape of the gases. The bulbous form of the blood receiver prevents the blood from frothing over into the pump; and if the action becomes too violent, it can be immediately allayed by pouring a few drops of warm water on to the tube (E). The bubbles are thereby driven back into the receiver, and the pump is never fouled. The tap (D) is so manipulated that the gases only, and not the water which condenses in the reservoir (B), are driven over into the eudiometer. The water is returned back into the blood-receiver. Three or four exhaustions are sufficient to extract all the gases from about 10 gms. of blood.
\end{abstract}

Barcroft (1899-1900) and his associates, concerned with the study of metabolism in the organs of small animals and so forced to work with very small quantities of blood, modified Bohr's mercurial air pump (Bohr and Torup, 1891) and for a decade the 'Toepler pump' with many a 'simplification' competed with the newer methods developed by Barcroft in Cambridge, Haldane in Oxford, and the two in collusion, about to be described.

\section{FERRICYANIDE}

A new departure arose from Haldane's (1897-98) observation that when potassium ferricyanide is added to a 'not too dilute solution of blood in water' bubbles of gas'nearly pure oxygen' on examination-are evolved at the same time as methaemoglobin is formed. Haldane realised that ferricyanide, by releasing the gas combined with haemoglobin in solutions of oxyhaemoglobin and carboxyhaemoglobin, might provide an alternative to the troublesome, time-consuming pump. Methaemoglobin formation on the addition of ferricyanide was known to von Mering (1883) and Hufner (1894), and, indeed, Hoppe-Seyler (1889) surmised that the change entailed oxidation of the ferrous iron in oxyhaemoglovin to ferric in methaemoglobin, but Haldane was the first to note that free oxygen was released in the process. To measure 

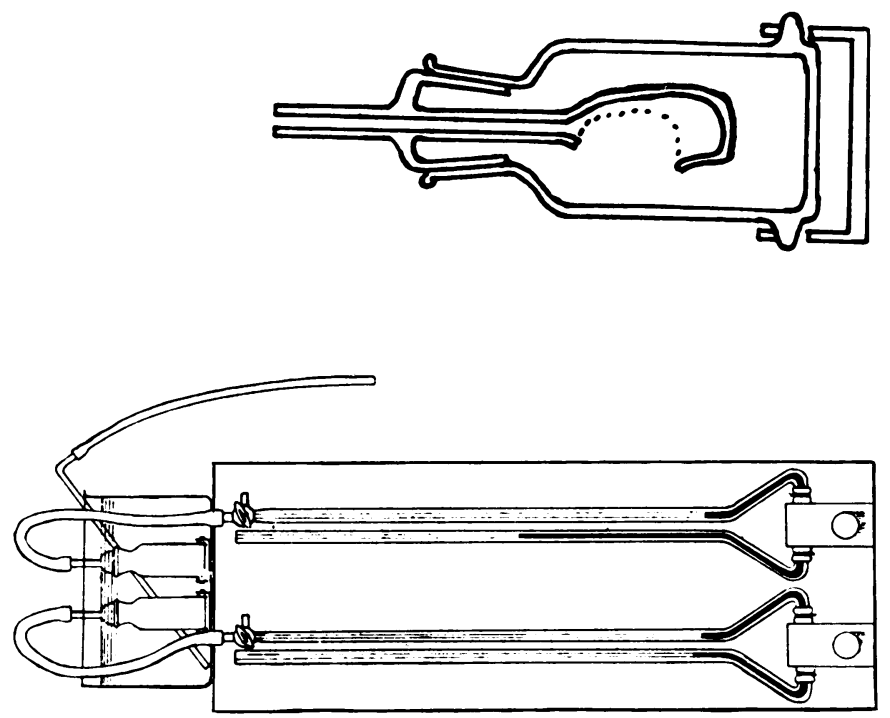

$\stackrel{\infty}{20}$

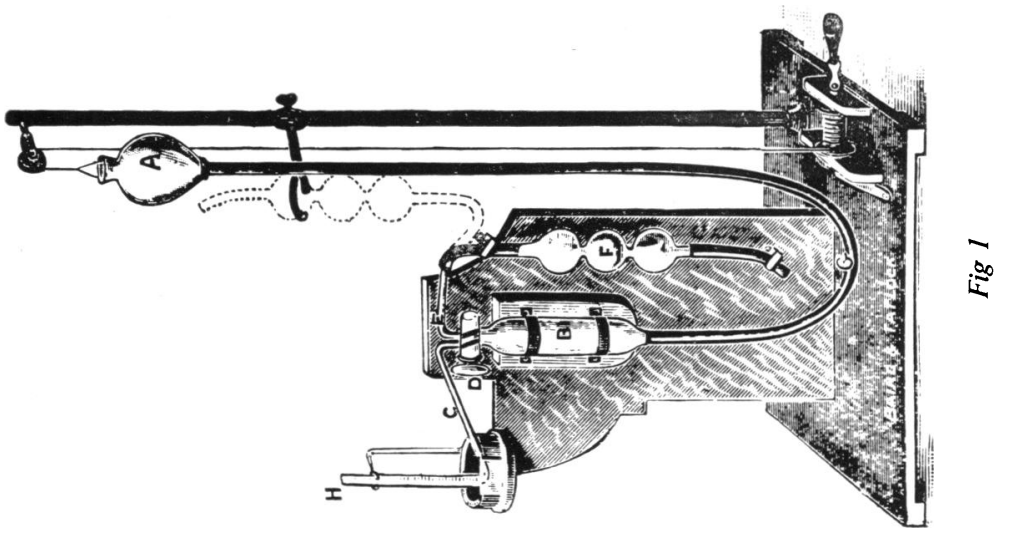



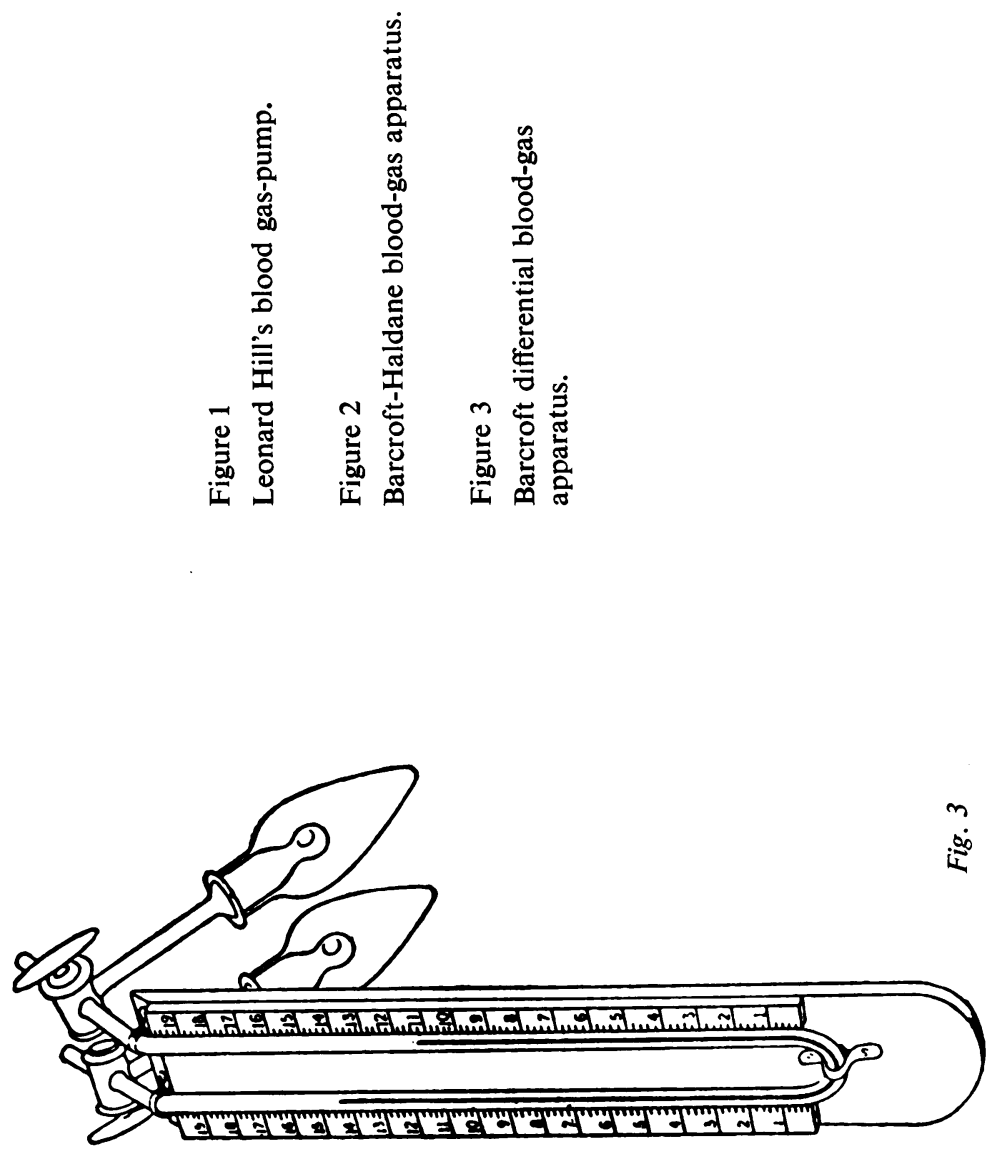

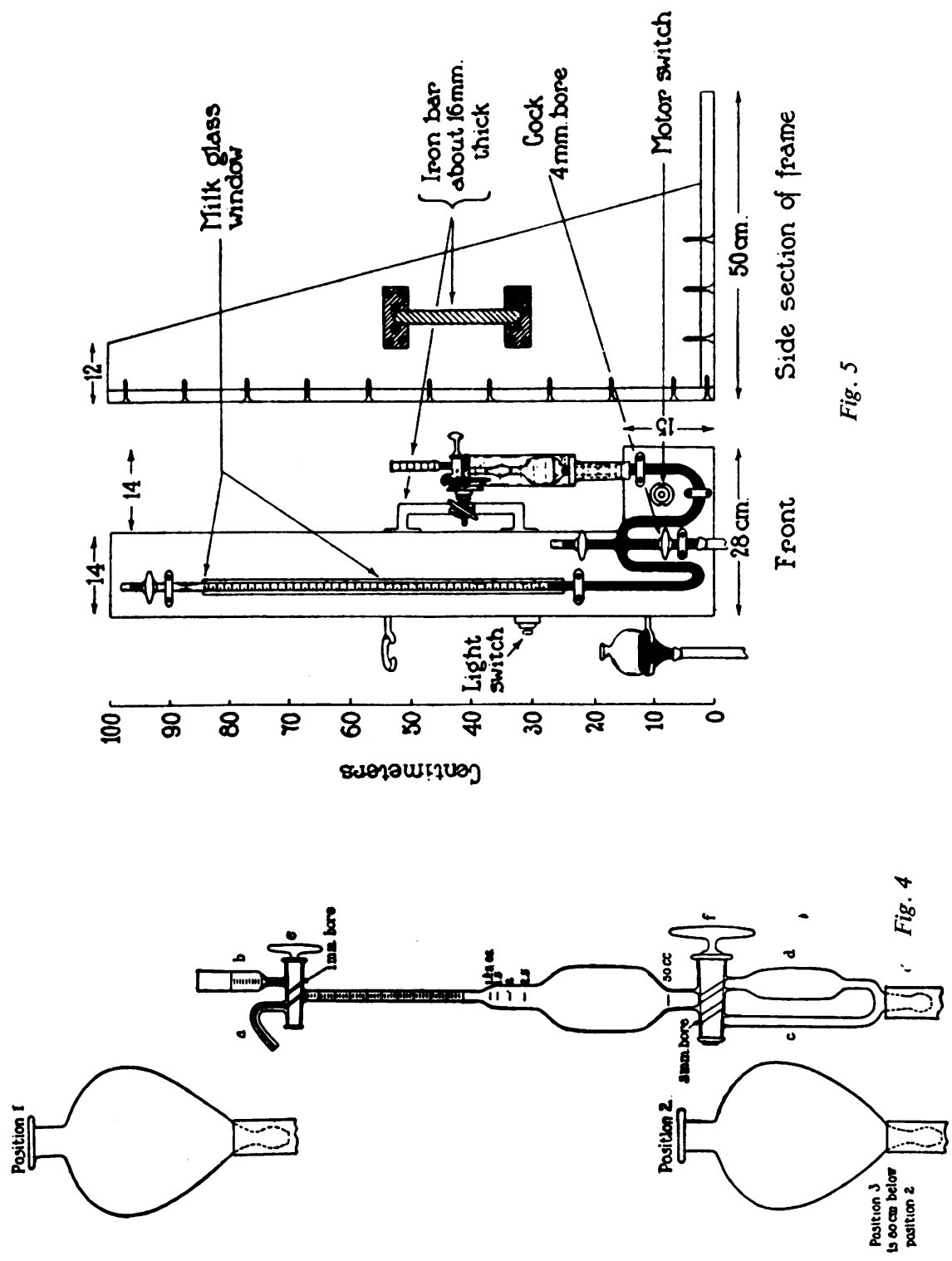




$\dot{0}$
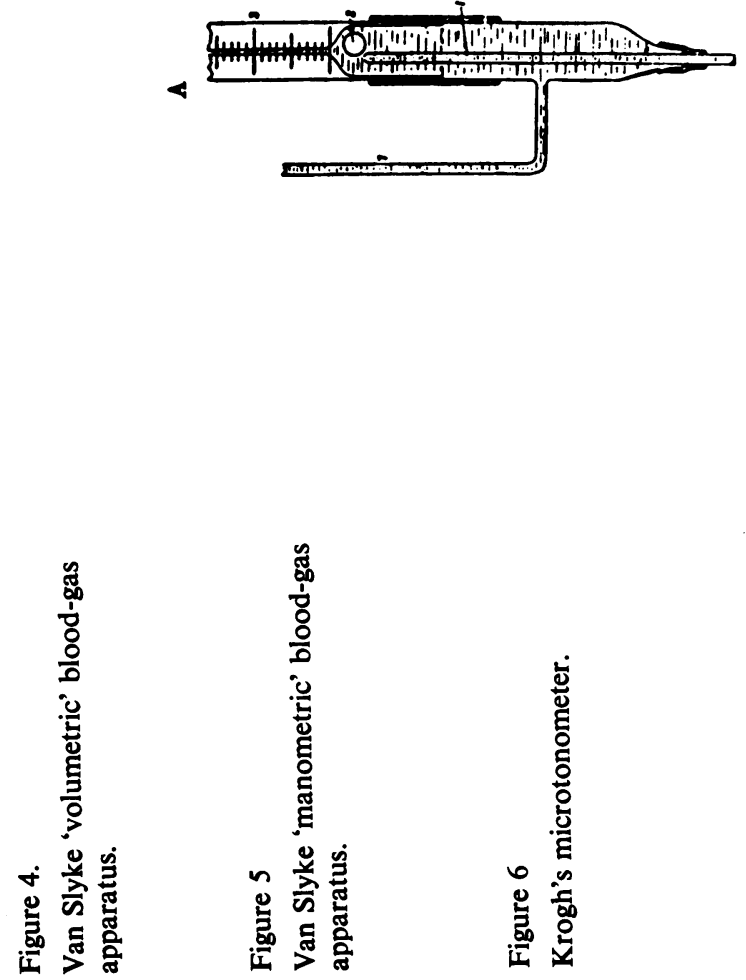


\title{
The Development of Blood Gas Analysis
}

the volume of gas evolved Haldane tried many a plan 'but ... the most convenient arrangement was finally found to be an apparatus arranged similarly to the well known apparatus of Dupré with one or two modifications.' Blood, to which alkali was added to prevent evolution of carbon dioxide, was measured into a flask or bottle and ferricyanide was poured into a small tube placed upright in the flask, which was closed and connected to a burette closed at its lower end by a flexible water seal by which pressure changes could be compensated (equilibrated). The flask was immersed in a water-jacket and as soon as the burette reading was constant (about three minutes), the flask was tilted so as to upset the tube of ferricyanide, and shaken for as long as gas was evolved. The flask was again shaken after a burette reading until a constant result was obtained (fifteen minutes usually). Even when Haldane (1899-1900) used this method to determine the oxygen capacity of blood, his technique demanded $20 \mathrm{ml}$., a quantity far in excess of that available to Barcroft (1899-1900) in his study of the gaseous metabolism of the submaxillary gland which was published in the same volume of the Journal of Physiology and described a 'Toepler pump for small quantities of blood'. Oxford's ferricyanide was the answer to the Cambridge problem and the two physiologists combined to develop 'a method of estimating the oxygen and carbonic acid in small quantities of blood'. But the modified Toepler lasted a decade (Buckmaster and Gardner, 1910).

Rather than measure the volume of the gas evolved Barcroft and Haldane (1902) decided, as would Van Slyke later on, that observation of the pressure change was fraught with less error:

\begin{abstract}
The apparatus consists of a small glass vessel attached by tubing to a pressure-gauge of narrow bore. The vessel is so arranged that oxygen in the sample of blood can be liberated within by ferricyanide and the resulting increase of pressure measured by means of a gauge. From the increase of pressure the volume of oxygen can be calculated. By similar manipulation with the use of tartaric acid in the place of ferricyanide the carbonic acid is subsequently determined.

The whole apparatus is shown in Figure 2. Two gauges, one connected with the blood-gas vessel, and the other with a precisely similar control, to form a convenient background for reading the graduations on the tube. Each gauge is graduated on both limbs in millimeters. . . The limbs of each gauge are connected below by a piece of rubber tubing which can be compressed by a screw clamp so as to adjust the limbs. The gauges are filled with water which may be tinged with a suitable dye ... one limb of each gauge is provided with a 3-way tap close to the top.... The blood-gas and control vessel . . . each have a capacity of about $25 \mathrm{ml}$. The stopper is perforated by a glass tube of narrow bore; which passes below into an open pocket capable of holding about $0.3 \mathrm{ml}$. of liquid. The pocket is so arranged that any liquid in it can easily be emptied by tilting the vessel. To this end the orifice above the pocket should be at least $1.8 \mathrm{~cm}$. in height and as broad as possible. ... Before the sample of blood is collected, $1.5 \mathrm{ml}$. of dilute (to haemolyse the red cells) ammonia (to prevent escape of carbon dioxide) solution is pipetted into the blood-gas vessel, and $0.25 \mathrm{ml}$. of saturated ferricyanide solution is placed in the glass pocket of the stopper which has previously been greased. . . By calculation $\mathrm{mm}$. on manometer scale can be converted to volumes of gas liberated.
\end{abstract}

Haldane and Barcroft were entitled to claim that their apparatus in spite of the small volume of blood used . . . is not much less accurate than the blood-pump with much larger quantities of blood,' care being taken with the details of technique.

Brodie (1909-10) described a modification of the Barcroft-Haldane method, but years later Haldane (1919-20) went back to the general principle of the simple Haldane (1900) apparatus, altered to increase its accuracy with small samples of arterial or venous blood. Gas volumes were read on a burette and a levelling tube compensated 


\section{S. Breathnach}

for pressure changes, the whole apparatus being immersed in a water bath. Oxygen capacity was measured with ferricyanide and oxygen content by noting the volume absorbed by the blood from the air in the containing flask.

Because his original interest was in the amount of oxygen used and of carbon dioxide given out by the organ under study (i.e. in tissue metabolism), Barcroft (1908) was concerned not with the absolute amount of gas in any particular sample of blood but with the difference between the gas contents of samples of arterial and venous blood. And since 'the difference between the amount of oxygen in two samples of blood from the same animal may be estimated as the difference between the amounts of oxygen necessary to saturate each sample' Barcroft shrewdly decided to measure the difference between the amounts of oxygen necessary to saturate the two samples of blood rather than that between the amounts releasable from them. The apparatus consisted of a manometer each limb of which could be opened to the air, as well as being attached to a bottle, the two bottles being as nearly as possible of the same size and calibrated (Fig. 3). Equal quantities of arterial and venous blood placed in the two bottles were shaken in a water bath until thoroughly saturated when the new levels in the manometer were read. Barcroft was indebted to his fatherin-law, Sir Robert S. Ball for the calculation converting the manometric reading into gas volumes. (Subsequently A. V. Hill (1915-16) calculated the relationship between change of level and the differential absorption of gas more accurately to take account of inequalities between the capacities of the two small bottles.) In use the differential apparatus was modified slightly, particularly with regard to simplifying calibration.

\section{SYNTHESIS}

Methods based on boiling the gas out of solution under diminished pressure had 'been completely displaced by the Barcroft-Haldane methods with their relative rapidity and simplicity' when Van Slyke $(1914-15,1916-17,1917,1924,1927)$ revived the vacuum extraction procedure shrewdly combining it with the chemical methods used to free the gases that had blossomed with Haldane's introduction of ferricyanide. By removing the liquid instead of the gas (as had been attempted in the earlier 'pumps') from the chamber, after the extraction, so that the gases could be measured over mercury in a calibrated capillary tube at the top of the same chamber, Van Slyke immeasurably simplified the technique and made the entire operation possible with a one-piece apparatus. A further aid to simplicity arose from Hulett's suggestion, from his work on natural waters (Swanson and Hulett, 1915), that complete extraction of the dissolved gases was unnecessary because distribution between the two phases (liquid and vapour) could be calculated in accordance with Henry's law.

In his studies on acidosis Van Slyke was concerned with the carbon dioxide capacity of plasma, and his preliminary account of his volumetric method shows how simple the vacuum extraction procedure became in his hands (Van Slyke, Stillman and Cullen, 1914-15), Fig. 4:

... A Simple apparatus was devised which permits, in three or four minutes, a determination of the $\mathrm{CO}_{2}$ content with an accuracy within $1 \%$. It consists essentially of a $50 \mathrm{ml}$. pipette, provided with three-way stopcocks at the top and bottom, and connected with a mercury bulb. The pipette being full of mercury, $1 \mathrm{ml}$. of plasma, washed in with $1 \mathrm{ml}$. of water and $0.5 \mathrm{ml}$. $\mathrm{N} / 1$ acid, is introduced through the upper cock (which is then closed). The mercury is then 


\section{The Development of Blood Gas Analysis}

drawn out from below by lowering the mercury bulb until a Torricellian vacuum is obtained in the pipette. The $\mathrm{CO}_{2}$ escapes from solution as the result of a few seconds shaking and the water solution is drawn out of the pipette at the bottom (into a trap). The mercury is then let in again through the other entrance of the three-way cock at the bottom, and the volume of $\mathrm{CO}_{2}$ is read in the upper stem of the pipette, which is calibrated in $0.02 \mathrm{ml}$. divisions (later $0.01 \mathrm{ml}$.).

The alternative pathways, through the 'trap' or 'bypass', beneath the bottom stopcock allowed easy separation of liquid from gas, the volume of which could then be read at barometric pressure and room temperature (Van Slyke, 1917). Using the 'pipette' for oxygen determination in blood (1916-17) presented no problems particularly after Poulton's (1919-20) modification of de-aerating the ferricyanide in the apparatus and introducing the blood directly into the reaction chamber.

In the 'volumetric' method just described, the pressure was brought always to atmospheric and the gas volume read on a scale. To increase accuracy, as much as ten or even a hundred times, the 'manometric' method was introduced (Van Slyke and Neill, 1924; Van Slyke, 1927). In the new method the gas volume was brought to an arbitrarily chosen size, and the amount of gas determined from the pressure exerted on a manometer. To do this the original $50 \mathrm{ml}$. pipette was connected with a levelling bulb and mercury manometer (Fig. 5). The infinite capacity for taking pains over technical minutiae is a rare gift, yet it is curious how Van Slyke, like Claude Bernard and Carl Ludwig with Lesage and Salvenmoser respectively, found someone so accomplished. In Volumetric Methods (Peters and Van Slyke, 1932) he wrote: 'This [manometric] apparatus can not be introduced without acknowledging its debt to the skill and precision of John Plazin, the writer's technical assistant for the past seventeen years. Plazin constructed the first manometric apparatus, and performed many of the analyses in the development of manometric methods for the blood gases, and for other substances.'

In 1928 Barcroft and his associates (Abeloos et al., 1928) showed that the Barcroft differential and Haldane constant pressure gas analysis model gave lower values for the oxygen capacity of haemoglobin than did the 'volumetric' Van Slyke apparatus, which itself agreed with the old blood gas pump of Barcroft and Roberts (1914); thereafter the final arbiter in blood gas quantitation was the 'manometric' apparatus.

\section{THE AEROTONOMETER}

Quite another approach, first applied in Pfluger's laboratory in Bonn, was based upon the aerotonometer in which a stream of blood was conducted over a sample of gas (presenting as large a surface as possible) with which the blood came into equilibrium. From the composition of the equilibrated gas determined by subsequent analysis, the tension of the blood gases could be derived. The principle was discussed by Pfluger (1872) and the method described in detail by his pupil Strassburg (1872). Relatively large quantities of atmospheric air were used and equilibration was slow; the technique was cumbrous and the results poor. Bohr $(1887,1891,1905)$ working originally in Ludwig's laboratory, and Fredericq (1893-94) adapted Ludwig's stromuhr, so that the air was exposed to the blood in two intercommunicating cylinders which were connected into the circulation. Oxygen was not a problem with Fredericq's method but the carbon dioxide estimations were unsatisfactory. 


\section{S. Breathnach}

By reducing the size of the air bubble to a diameter of $2 \mathrm{~mm}$. Bohr's protégé, Krogh (1908), ensured rapid equilibration and established standards of accuracy beyond challenge, at the same time requiring but small quantities of blood. Krogh's microtonometer (Fig. 6) consisted of two distinct parts, one of which was an apparatus for the microanalysis of the gas bubble. Blood from the arterial cannula entered the tonometer from below in a fine jet and kept the gas bubble oscillating on its course to the exit through a side-tube, where it could be collected and later re-infused into the animal. During the course of an experiment the volume of the gas bubble was measured from time to time, a constant volume indicating the end-point. By means of an iron screw moving in mercury the bubble was finally brought up into the micro-analyser-a graduated capillary tube housed in a water-jacket to prevent temperature changes-where gas absorptions were performed one after another by the usual reagents. Krogh found that the arterial blood oxygen tension in rabbits was invariably lower ( 8 to $30 \mathrm{~mm}$. $\mathrm{Hg}$.) than in the alveolar air and that the alveolar diffusion velocity was sufficient to supply maximum oxygen demands. The microtonometer was unsuited to human application, however, and although Barcroft's results were convincing to everyone except Haldane, it was not until the Van Slyke manometric apparatus arrived that blood gas determination became incontrovertible.

In 1921 Barcroft and Nagahashi used the principle of aerotonometry for the direct measurement of the partial pressure of oxygen in human blood. Blood was withdrawn into a $10 \mathrm{ml}$. syringe and transferred to another syringe containing enough mercury to fill the dead-space and in addition a bubble of alveolar air so small that any change that took place between the blood and the air would not alter the composition of blood. 'The method was an obvious adaptation to human beings of that so brilliantly devised by Krogh for rabbits.' A decade later Ferguson (1932) combined the microtonometer and analyser in a single pipette with which it was possible to measure the tension of carbon dioxide in $2 \mathrm{ml}$. of blood.

Although not based on the principle of the aerotonometer Roughton and Scholander (1943) developed the idea of a one-piece syringe and gas analyser, the latter closely resembling Krogh's graduated capillary tube. In this method the oxygen, carbon monoxide and nitrogen of the blood and reagents were extracted (as Nasse had done in 1816) by means of excess carbon dioxide, the carbon dioxide being then absorbed with 10 per cent hydroxide. By driving the residual gas bubble into the capillary and measuring its volume before and after absorption with alkaline pyrogallol the oxygen content could be determined, allowance being made for a blank determination. Riley, Proemmel and Franke (1945) adapted the Roughton and Scholander syringe analyser for the direct microtonometric analysis of the blood gases. Similar in principle to the bubble tonometer, Krogh's precision was rivalled when Lambertsen, Bunce, Drabkin and Schmidt (1952) enlarged the syringe and lengthened the graduated capillary.

\section{THE MODERN ERA}

Confirmatory but altogether independent means of estimating blood oxygen levels developed from Stokes's (1864) description of the spectral difference between oxygenated and reduced haemoglobin, or scarlet and purple cruorine as he called them. Vierordt $(1873,1876)$ discovered the first practical method of determining the 


\section{The Development of Blood Gas Analysis}

extinction coefficient, and by its relation to concentration developed a general method for quantitative analysis of colouring matters. In 1894 Hufner determined the spectrophotometric constants of haemoglobin and its compounds with oxygen and carbon monoxide, and by spectrophotometry succeeded in determining the absolute and relative amounts of reduced and oxyhaemoglobin existing side by side in the blood. Hufner also determined that 1 gram of reduced haemoglobin (ox) combined with $1.338 \mathrm{ml}$. of oxygen or carbon monoxide (S.T.P.), a factor which permitted calculation of the oxygen capacity of blood without recourse to gas analysis. Spectrophotometric instruments for the continuous measurement of blood oxygen saturation in vivo were designed by Kramer (1934) and Matthes (1934, 1935, 1939); direct readings, partially corrected for changes in quantity of haemoglobin in the light path, were possible by methods invented independently by Millikan and by Goldie in 1942 . By 1949 an oximeter that had solved the problem of getting absolute saturation values directly (incident light measured by initial compression thus making the path 'bloodless') was described by Wood and Geraci (1949). In vitro spectrophotometric methods were developed very shortly afterwards (Nahas, 1951; Wade, Bishop, Cumming and Donald, 1953) and found widespread clinical acceptance.

Gas-liquid chromatography has also been used as a means whereby the gases in biological fluids can be analysed (Ramsay, 1959; Brenner and Cisplinski, 1959). This technique depends on the physical separation of a moving gas phase by adsorption on a stationary phase consisting of liquid-coated inert granules or silica gel. In chromatography separation of a mixture is based on the affinity of the components for the stationary phase. Gases which are strongly attracted to the stationary phase move through the column at a slower rate and appear at the end of the column later than the components that have shown an indifference towards the stationary phase. When the component arrives at the end of the column it is detected and measured by a thermistor (i.e. a ceramic material with a high thermal coefficient; a tiny change in temperature of the enveloping gas, as reflected by its thermal conductivity, will markedly alter its electrical resistance). As the thermal conductivity changes with the specific gas being detected, a related change in the electrical conductivity of the thermistor occurs. This change in electrical resistance is displayed potentiometrically on a sensitive recorded by means of a Wheatstone bridge. As each component gas is detected a characteristic curve (chromatogram) is produced and can be readily identified by comparing it with a known or predetermined chromatogram of a similar mixture. In operation the gas-liquid chromatograph is temperamental and demanding.

The development of plastic membranes permeable to oxygen and carbon dioxide but not to water or ions, helped by the modern advance in electronic engineering made possible the construction of electrodes with which the tensions of these gases could be measured with extraordinary facility. The electrodes for the two gases are inherently different in principle, but are usually mounted together in a small water bath, the temperature of which can be accurately controlled (Severinghaus and Bradley, 1958). The oxygen electrode introduced by Clark in 1958 is a polarographic cell made up of a silver-silver chloride reference electrode and a platinum cathode. Oxygen gas in solution reacts the negatively polarised platinum surface and becomes hydroxyl ions. By interposing a polyethylene membrane between the unknown solution 


\section{S. Breathnach}

and the cathode surface, proteins and many other substances which would otherwise poison the surface or alter its reactivity are prevented from doing so. The membrane offers free passage to oxygen and the current passing through the cell is directly proportional to the oxygen tension outside the membrane. Usually a transistorized null balance meter is used to measure the oxygen current. The possibility of determining the tension of carbon dioxide in a liquid by measuring the $\mathrm{pH}$ of a film of water separated from the sample by a rubber membrane, which is freely permeable to that gas, was first examined by Stow and his associates (1957). Greater sensitivity and stability are ensured by allowing the carbon dioxide to diffuse through a Teflon or silastic membrane from the unknown sample into an aqueous bicarbonate layer held in a cellophane or nylon film on the surface of a conventional $\mathrm{pH}$ glass electrode (Severinghaus and Bradley, 1958; Severinghaus, 1968). The measured $\mathrm{pH}$ is altered in direct proportion to changes in the logarithm of the carbon dioxide tension; the Teflon or silastic membrane, being impermeable to ions, prevents the $\mathrm{pH}$ of the sample from affecting the $\mathrm{pH}$ at the glass electrode surface, which of course is registered on a conventional meter. By facilitating rapid semi-skilled determination of the blood gases these electrode systems have found widespread clinical favour.

\section{SUMMARY}

Inspired by Gustav Magnus the great physiologists of the nineteenth century addressed themselves to the problems of blood gas analysis, but it was not until the early decades of the new century that the respiratory function of the blood was finally elucidated, largely as a result of technical innovations introduced by Haldane and Barcroft, by Krogh and Van Slyke. Through equipment and methods that do not require their dexterity and skill, the accuracy and precision that these men brought to their work is available today to all. But the information they gleaned through their ingenuity and assiduity is imperishable.

\section{ACKNOWLEDGEMENTS}

This study was made with the help of a Wellcome Trust Fellowship.

Charming cameos of many of the twentieth-century physiologists mentioned above will be found in the reminiscences of Dr. Donald Van Slyke (1964) who very kindly sent me a reprint of his lecture to which my attention had been drawn by Professor Henry Barcroft.

\section{REFERENCES}

Abeloos, M., Barcroft, J., Cordero, N., Harrison, T. R. and Sendroy, J., 'The measurement of the oxygen capacity of haemoglobin', J. Physiol., 1928, 66, 262-66.

BARCROFT, J., 'The gaseous metabolism of the submaxillary gland. Part I. on methods, with a description of an appartus for gas analysis', J. Physiol., 1899-1900, 25, 26592; ibid., 1905, 32, 1 ; ibid., 1908, 37, 1v; BarCROFT, J. and ROBERTs, Ff., ibid., 1909-10, 39, 429-37; BuCKMASTER, G. A. and GARDNER, J. A., ibid., 1910, 40 373-77; HARTRIDGE, H., ibid., 1912, 44, 1-12.

Barcroft, J., 'Differential methods of blood-gas analysis', J. Physiol., 1908, 37, 12-26; BARCROFT, J. and ROBERTS, Ff., ibid., 1909-10, 39, 429-37; BARCROFT, J. and HIGGINS, H. L., ibid., 1911, 42, 512-18; BARCROFT, J. and BURN, J. H., ibid., 1912-13, 45, 493-97; Hoffman, P., ibid., 1913-14, 47, 272-74; Hill, A. V., ibid., 1915-16, 50, vii-ix.

BARCROFt, J. and HALDANe, J. S., 'A method of estimating the oxygen and carbonic acid in small quantities of blood', J. Physiol., 1902, 28, 232-40; BrodIE, T. G., ibid., 1909-10, 39, 391-96; BarCroft, J. and Morawitz, P., Deut. Arch. klin. Med., 1908, 93, 223-31. 


\section{The Development of Blood Gas Analysis}

Barcroft, J. and Nagahashi, M., 'The direct measurement of the partial pressure of oxygen in human blood', J. Physiol., 1921, 55, 339-45.

BERnARD, C., 'Determination au moyen de l'oxyde de carbone, des quantitas d'oxygène que contient de sang veineux des organes glandulaires à l'état de fonction et à l'état de repos', C. r. hebd. Acad. Sci. Paris, 1858, 47, 393-400; NAwrockI, F., De Claudii Bernardi methodo oxygenu copiam in sanguine determinandi, Bratislava, 1863; 'Ueber die Methoden den Sauerstoff im Blute zu bestimmen', Stud. Physiol. Inst. Breslau, $1863,2,144$.

Bert, P., Barometric Pressure, Researches in Experimental Physiology, 1878, trans. by Mary A. Hitchcock and F. A. Hitchcock, Columbus, Ohio, College Book Co., 1943 , pp. 509-11; 582-85.

BoHR, C., 'Ueber die Gaspannungen im Lebenden arteriellen Blute', Centralb. Physiol., 1887, 1, 293-99; Skand. Arch. Physiol., 1891, 2, 236-68; ibid., 1905, 17, 205-10.

BOHR, C. and TORUP, SOPH., 'Der Sauerstoffgehalt der oxyhaemoglobin Krystalle', Skand. Arch. Physiol., 1891, 3, 69-75.

BOYLE, R., 'The continuation, promised in the preceding tract and communicated by the same noble author, in ten other titles', Phil. Trans. $R$. Soc. Lond., 1670, 5, 2035-56.

BRENNER, N, and Cisplinski, E., 'Gas chromatographic analysis of mixtures containing oxygen, nitrogen and carbon dioxide', Ann. N. Y. Acad. Sci., 1959, 72, 705-13.

Clark, L. C. Jr., 'Monitor and control of blood and tissue oxygen tensions', Trans. Am. Soc. artif. internal Organs, 1956, 2, 41-48.

Davy, H., Gilbert's Ann., 1803, 19, 308, cited by Magnus (1845), p. 181; Ann. Phys. Chem., $1803,12,574-593$.

DE MARTIGNY, C., 'Recherches experimentales et critiques sur l'absorption et sur l'exhalation respiratoires', J. Physiol., 1830, 10, 111-61.

Ferguson, J. K. W., 'A method to measure the tension of carbon dioxide in small amounts of blood', J. Biol. Chem., 1932, 95, 301-10.

FrederiCQ, L., 'Ueber die Tension des Sauerstoffes und der Kohlensaure in arteriellen Peptonblute', Centralb. Physiol., 1893-94, 7, 33-38.

Goldie, E. A. G., 'A device for the continuous indication of oxygen saturation of circulating blood in man', J. Sci. Instr., 1942, 19, 23-25.

Haldane, J. S., 'A contribution to the chemistry of haemoglobin and its immediate derivatives', J. Physiol., 1897-98, 22, 298-306; ibid., 1899-1900, 25, 295-302; J. Path. Bact., 1919-20, 23, 443-50.

HIIL, L., 'A simple form of gas pump', J. Physiol., 1894-95, 17, 353-55; HILL, L. and NABARRO, D. N., ibid., 1895, 18, 218-29.

Hoppe SeYler, F., 'Beitrage zur Kentniss des Blutfarbstoffes', Zt. physiol. Chem., 1889, 13, 477.

HuFNER, G., 'Neue Versuche zur Bestimmung des Sauerstoffcapacitat des Blutfarbstoffs', Arch. Anat. Physiol., 1894, 130-76.

KRAMER, K., 'Bestimmung der Sauerstoffgehaltes und der Hamoglobin-konzentration in Hamoglobinlosungen und hamoloysiertem Blut auf lichtolektrischem Wege', Zt. Biol., 1934, 95, 126-34; in ABERHALDEN, EMIL, Handbuch der biologischen Arbeitsmethoden, 1934, 5, 1085-1112; Klin. Wschr., 1934, 13, 379-80.

KROGH, A., 'Some new methods for the tonometric determination of gas-tension in fluids', Skand. Arch. Physiol., 1908, 20, 259-78; 'On micro-analysis of gases', 1908, ibid., 20, 279-88.

Lambertsen, C. J., Bunce, P. L., Drabkin, D. L. and Schmidt, C. F., 'Relationship of oxygen tension to haemoglobin oxygen saturation in the arterial blood of normal men', J. appl. Physiol., 1951-52, 4, 873-85.

MAgnus, G., 'Ueber die im Blute enthaltenen Gase, Sauerstoff, Stickstoff und Kohlensaure', Ann. Physik., 1837, 12, 583-606, (Ann. Physik. Chem., 40); 'Ueber der Absorptionsvermogen des Bluts fur Sauerstoff', Ann. Physik. Chem., 1845, 66, 177-208.

MATthes, K. and Gross, F., 'Untersuchungen ueber die Absorption von rotem und 


\section{S. Breathnach}

ultrarotem Licht durch Kohlenoxydgesaltigtes, sauerstoffgesaltigtes und reduziertes Blut', Arch. exper. Path. Pharmakol., 1939, 191, 369-80; 381-90; 523-28; 706-14.

MeYer, L., 'Die Gases des Blutes', Zeit. rat. Med., 1857, 8, 256.

MrllikAN, G. A., 'The oximeter, an instrument for measuring continuously the oxygen saturation of arterial blood in man', Rev. Scient. Instr. 1942, 13, 434-44.

NaHAS, G. G., 'Spectrophotometric determination of haemoglobin and oxygen in whole hemolysed blood', Science, 1951, 113, 723-25.

Nasse, - 'Untersuchungen ueber das Athmen', Dt. Arch. Physiol., 1816, 2, 195-240; 2, 435-70

Peters, J. P. and Van Slyke, D. D., Quantitative Clinical Chemistry, London, Baillière, Tindall \& Cox, 1932, Vol. II, p. 267, footnote.

Pfluger, E., 'Zur Gasmotrie des Blutes', Centralb. med. Wiss., 1866, 4, 305-8; ZunTz, N., ibid., 1867, 5, 529-33; Pfluger, E., ibid., 1867, 5, 722-26; Pfluger, E. and ZunTz, N., Arch. ges. Physiol., 1868, 1, 361-74.

Pfluger, E., 'Die Topographie der Gasspannungen im thierischen Organismus', Arch. ges. Physiol., 1872, 6, 43-64; STRASSBURG, G., ibid., 1872, 6, 65-96.

Poulton, E. P., 'Modification in the technique of estimating oxygen in blood with Van Slyke's apparatus', J. Physiol., 1919-20, 53, 1xi-lxii.

RAMSEY, L. H., 'Analysis of gas in biological fluids by gas chromatography', Science, $1959,129,900-1$.

Riley, R. L., Proemmel, D. D. and Franke, R. E., 'A direct method for the determination of oxygen and carbon dioxide tensions in blood', J. Biol. Chem., 1945, 161, 621-33.

Roughton, F. J. W. and Scholander, P. F., 'Micro-gaso-metric estimation of the blood gases', J. Biol. Chem., 1943, 148, 550; 551-64; 565-72; 572-80.

Setchenow, J., 'Beitrage zur Pneumatologie des Blutes', Sber. Akad. Wiss. Wien. (Math. Kl.), 1859, 36, 293; 'Neuer Apparat zur Gewinnung der Gase ans dem Blute', Z. rat. Med., $1865,23,16-20$.

Severinghaus, J. W. and Bradley, A. F., Jr., 'Electrodes for blood $\mathrm{Po}_{2}$ and $\mathrm{PcO}_{2}$ determination', J. appl. Physiol., 1958, 13, 515-20; Severinghaus, J. W., Ann. N. Y. Acad. Sci., 1968, 148, Art. 1, 115-32.

Stokes, G. G., 'On the reduction and oxidation of the colouring matter of the blood', Proc. roy. Soc., 1864, 13, 355-64.

Stow, R. W., BaER, R. F. and RANDAll, B. F., 'Rapid measurement of the tension of carbon dioxide in blood', Arch. phys. Med. Rehab., 1957, 38, 646-50; [Abstract] 'Electrical measurement of $\mathrm{PcO}_{2}$ of blood', Amer. J. Physiol., 1954, 179, 678.

Van Slyke, D. D., Stillman, E. and Cullen, G. E., 'The nature and detection of diabetic acidosis', Proc. Soc. exp. Biol. Med., 1914-15, 12, 165-66; Van Slyke, D. D., ibid., 1916-17, 14, 84-85; J. Biol. Chem., 1917, 30, 347-68.

VAN SLYKe, D. D., and NeILL, J. M., 'The determination of gases in blood and other solutions by vacuum extraction and manometric measurement', J. Biol. Chem., 1924, 61, 523-73; VAN SLYKe, D. D., ibid., 1927, 73, 121-26.

Van Slyke, D. D., 'The Gases of the Blood', Brookhaven Lecture Series, No. 41, 1-16. Brookhaven National Laboratory, 1964.

VIERORDT, K., Die Anivendung des Spectral-apparatus zur Photometrie der Absorptionspectren und zur quantitativen chemischen Analyse, Tubingen, 1873. Die quantitative Spektralanalyse in ihrer Anivendung auf Physiologie, Physik, Chemie, und Technologie, Tubingen, 1876.

Von Mering, 'Ueber die Wirkung des Ferricyankalium auf Blut', Zt. physiol. Chem., 1883, 8, 186-89.

Wade, O. L., Bishop, J. J., Cumming, G. and Donald, K. W., 'Method for the rapid estimation of percentage oxygen saturation and oxygen content in blood', Brit. med. J., 1953, ii, 902-7.

Wood, E. H. and Geraci, J. E., 'Photoelectric determination of arterial oxygen saturation in man', J. lab. clin. Med., 1949, 34, 387. 